\title{
Studi Pertumbuhan Portunus pelagicus Linnaeus, 1758 (Portunidae:Malacostrata) di Perairan Tunggulsari, Rembang
}

\author{
Diah Ayu Mustofa*, Sri Redjeki, Delianis Pringgenies \\ Departemen IImu Kelautan, Fakultas Perikanan dan IImu Kelautan, Universitas Diponegoro \\ Jl. Prof H.Soedharto S H, Tembalang, Semarang, Jawa Tengah 50275 Indonesia \\ ${ }^{*}$ Corresponding author, e-mail : diahamustofa@gmail.com
}

\begin{abstract}
ABSTRAK : Rajungan merupakan komoditas perikanan yang banyak diminati baik dalam maupun luar negeri. Permintaan rajungan meningkat setiap tahunnya. Desa Tunggulsari merupakan desa penghasil rajungan di Rembang. Desa ini terletak di Kecamatan Kaliori dengan 78,35\% penduduknya nelayan. Penangkapan rajungan terjadi setiap hari tanpa adanya restocking. Kondisi ini dapat menyebabkan overfishing dan berdampak pada kelestarian rajungan. Penelitian ini bertujuan untuk mengkaji pertumbuhan rajungan (Portunus pelagicus) hasil tangkapan nelayan di Desa Tunggulsari, Rembang meliputi distribusi lebar karapas dan pola pertumbuhan. Metode yang digunakan pada penelitian ini adalah deskriptif. Penelitian ini berlangsung selama 30 hari dengan pengambilan 100 sampel rajungan per hari. Hasil penelitian ini diketahui ukuran rajungan terdistribusi antara 49-178 $\mathrm{mm}$ dengan pola pertumbuhan allometrik negatif dengan nilai $\mathrm{b}=2,8575$. Berdasarkan penelitian terdapat $64 \%$ rajungan yang layak tangkap dan $36 \%$ rajungan yang tak layak tangkap meliputi rajungan muda berukuran $<10 \mathrm{~cm}$. Berdasarkan data, nelayan belum menerapkan PERMEN KP No. 12 Tahun 2020 tentang penangkapan rajungan. Hal ini akan berdampak pada kondisi rajungan di wilayah Tunggulsari.
\end{abstract}

Kata Kunci : Rajungan; Allometrik Negatif; Konservasi; Distribusi Ukuran

\section{Study of Portunus pelagicus Linnaeus, 1758 (Portunidae:Malacostrata) Growth in Tunggulsari waters, Rembang}

\begin{abstract}
Blue swimming crab fishery commodity that has high demand both at home and abroad. Tunggulsari is one of the villages in Rembang where people catch blueswimmingcrab. It's located in Kaliori Sub-district with $78.35 \%$ population of fishermen. Blue swimming crab is catched every day without any restocking. This condition cause overfishing and impact on the sustainability of blue swimming crab. This research aims to study the growth of blueswimming crab (Portunus pelagicus) in Tunggulsari, Rembang include distribution of width and growth pattern. The method used in this research is descriptive. This research lasted for 30 days by taking 100 sample/day. The results is the width is distributed between $49-178 \mathrm{~mm}$ and has a negative allometric growth pattern with value of $b=2.8575$. Based on the research, there are $64 \%$ blueswimming crab that worth to catch and $36 \%$ blueswimming crab that doesn't worth to catch include young crab which size $<10 \mathrm{~cm}$. Based on the data, fishermen have not implemented Government Regulation No. 12, 2020 regarding catching crabs. This impact on the condition of the crabs in the Tunggulsari area. Based on the research, there are $64 \%$ of crabs that are suitable for catching and $36 \%$ of crabs that are not suitable for catching include young crabs measuring $<10 \mathrm{~cm}$ Based on the data, fishermen have not implemented Government Regulation No. 12, 2020 concerning the Crab Regulation. This will have an impact on the chopping conditions in the Tunggulsari area.
\end{abstract}

Keywords : Blue Swimming Crab; Allometrik Negative; Conservation; Size Distribution

\section{PENDAHULUAN}

Indonesia merupakan negara maritim dengan laut seluas 3,25 juta $\mathrm{km}^{2}$ dan Zona Ekonomi Eksklusif 2,55 juta $\mathrm{km}^{2}$ (Badan Pusat Statistik, 2017), dengan luas wilayah lautan tersebut Indonesia memiliki keragaman dan kekayaan sumberdaya hayati laut, salah satunya adalah rajungan. Perairan Tunggulsari, Rembang merupakan salah satu wilayah penghasil rajungan di 
Indonesia. Berdasarkan data Keputusan Menteri Kelautan dan Perikanan Republik Indonesia Nomor 70/Kepmen-Kp/2016, penangkapan rajungan di Rembang sudah melampaui batas ambang dengan nilai 0,78 /tahun. Hal ini menunjukkan telah terjadi penangkapan yang berlebih (over exploited) di Perairan Rembang. Kondisi ini dapat disebabkan karena penangkapan rajungan dilakukan secara terus menerus tanpa adanya restocking. Setiap harinya, jumlah rajungan semakin terbatas namun jumlah kapal semakin bertambah. Untuk menghindari kondisi overfishing, Pemerintah mengeluarkan peraturan Menteri Kelautan dan Perikanan No.12 Tahun 2020 tentang pengelolaan penangkapan rajungan dimana rajungan dengan ukuran lebar $\leq 10 \mathrm{~cm}$ tidak boleh ditangkap.

Kurangnya informasi dalam penangkapan rajungan memicu terjadinya ekploitasi tak terkendali Penelitian ini bertujuan untuk mengkaji pertumbuhan rajungan (Portunus pelagicus) hasil tangkapan nelayan di Desa Tunggulsari, Rembang meliputi distribusi lebar karapas dan pola pertumbuhan. Dengan adanya informasi ini, diharapkan dapat menjadi acuan dalam penangkapan rajungan agar potensi rajungan dapat dimanfaatkan secara optimal

\section{MATERI DAN METODE}

Penelitian ini dilakukan selama 30 hari yaitu pada bulan Januari - Februari 2020. Sampel ini merupakan hasil tangkapan nelayan yang di daratkan di Desa Tunggulsari, Rembang. Sampel dipilih secara acak dan dilakukan pengukuran meliputi berat total rajungan dan lebar. Pengambilan data parameter lingkungan digunakan sebagai data pendukung penelitian.

Distribusi lebar karapas disajikan dalam bentuk diagram dengan proporsi sampel yang diperoleh (Walpole, 1992). Menentukan jumlah selang kelas dengan persamaan sebagai berikut,

$$
k=1+3,3 \times \log (n)
$$

Keterangan : $\mathrm{k}=$ jumlah selang kelas; $\mathrm{n}=$ jumlah total rajungan

Menentukan lebar kelas atau interval dengan persamaan sebagai berikut :

$$
\begin{gathered}
\mathrm{I}=\mathrm{r} / \mathrm{k} \\
\mathrm{r}=\text { nilai maksimum }- \text { nilai minimum }
\end{gathered}
$$

Keterangan $: \mathrm{I}=$ interval atau lebar kelas; $r=$ range; $\mathrm{k}=$ jumlah selang kelas

\section{Pola Pertumbuhan}

Analisis data untuk mengetahui hubungan lebar karapas dan berat total dilakukan menggunakan rumus sebagai berikut (Damora et al., 2016). Nilai b digunakan untuk menduga laju pertumbuhan kedua parameter yang dianalisis. Hipotesis yang digunakan : Jika $b=3$ merupakan pola pertumbuhan isometrik (pola pertumbuhan lebar sama dengan pertumbuhan berat); Jika b>3 merupakan pola pertumbuhan allometrik positif (pertumbuhan berat lebih cepat dari pada pertumbuhan lebar); Jika $b<3$ merupakan pola pertumbuhan allometrik negatif (pertumbuhan lebar lebih cepat dari pada pertumbuhan berat).

Berdasarkan prosedur Wibowo et al. (2019), Faktor kondisi dapat dihitung dengan menggunakan persamaan sebagai berikut :

$$
W r=\frac{w}{W S} x 100
$$

Keterangan : $\mathrm{Wr}=$ berat relatif; $\mathrm{W}=$ berat tiap rajungan; $\mathrm{Ws}=$ berat standar yang diprediksi

\section{Parameter Lingkungan}

Berdasarkan Wibowo et al.,(2019), parameter Lingkungan yang diukur meliputi DO, pH, suhu, salinitas. 


\section{Analisa Konservasi Sumberdaya Rajungan}

Analisa konservasi sumberdaya rajungan (Portunus pelagicus) mengacu pada Peraturan Menteri Kelautan dan Perikanan RI PERMEN KP No. 12 Tahun 2020 tentang Pengelolaan Lobster (Panulirus spp.), Kepiting (Scylla spp.), dan Rajungan (Portunus pelagicus)

\section{HASIL DAN PEMBAHASAN}

Distribusi ukuran rajungan dapat digunakan sebagai indikator baik buruknya penangkapan rajungan di suatu daerah . Berdasarkan hasil, rajungan terbanyak terdapat pada kelas 99-108 yaitu sebanyak 893 yang terdiri dari 497 ekor rajungan jantan dan 396 ekor rajungan betina. pada kelas 109-118, rajungan betina memiliki jumlah terbanyak yaitu 477 ekor sedangkan rajungan jantan sebanyak 338 ekor.

Variasi ukuran rajungan dapat dipengaruhi oleh beberapa faktor seperti jenis kelamin, umur, penyakit, parasit, ketersediaan makanan, kualitas air, dan hilangnya anggota tubuh (Hartnoll, 1982). Rajungan jantan memiliki ukuran tubuh lebih besar jika dibandingkan dengan rajungan betina. Hal ini sejalan dengan pendapat Kordi (1997), rajungan jantan dan betina dapat dibedakan berdasarkan warna dan ukurannya. Rajungan jantan mempunyai ukuran tubuh lebih besar dan capit lebih panjang daripada betina. Menurut Nugraheni et al.,(2015), intensitas penangkapan mempengaruhi variasi ukuran rajungan. Rajungan yang tertangkap pada wilayah perairan pantai memiliki ukuran yang lebih kecil jika dibanding dengan rajungan pada wilayah lepas pantai. Hal ini dipengaruhi oleh intensitas penangkapan yang cukup tinggi di wilayah perairan pantai.

Berdasarkan hasil penelitian dapat diketahui bahwa rajungan jantan memiliki nilai a $=0,000778$ dan nilai $b=2,4486$. Rajungan betina memiliki nilai $a=0,000151989$ dan nilai $b$ $=2,7873$. Nilai a total yaitu 0,000113 dan nilai $b$ total yaitu 2,8575 . Berdasarkan perhitungan Thitung > Ttabel yang berarti pertumbuhan rajungan allometrik (terima $\mathrm{Ho}$ ), dan nilai b pada rajungan jantan dan betina $<3$, maka dapat disimpulkan bahwa pola pertumbuhan rajungan jantan di Perairan Tunggulsari allometrik negatif, dimana pertumbuhan lebar karapas lebih cepat dibandingkan bobotnya.

Pola pertumbuhan rajungan di Perairan Tunggulsari yaitu allometrik negatif. Menurut Afifah et al. (2017), Pola pertumbuhan pada Portunidae tidak bersifat tetap dan dapat berubah ketika terjadi perubahan terhadap lingkungan dan ketersediaan makanan. Nilai b dipengaruhi oleh faktor internal dan eksternal. Faktor internal meliputi spesies, bentuk, dan kegemukan, sedangkan faktor eksternal meliputi musim, kondisi habitat, dan ketersediaan makanan (Hamid, 2019). Rajungan dengan lingkungan yang optimal akan tumbuh dengan optimal. Menurut Makahinda et al., (2018), rajungan yang tumbuh di lokasi yang berbeda akan memiliki pola pertumbuhan yang cenderung berbeda. Hal ini dipengaruhi oleh faktor eksternal. Faktor eskternal yang mendukung pertumbuhan

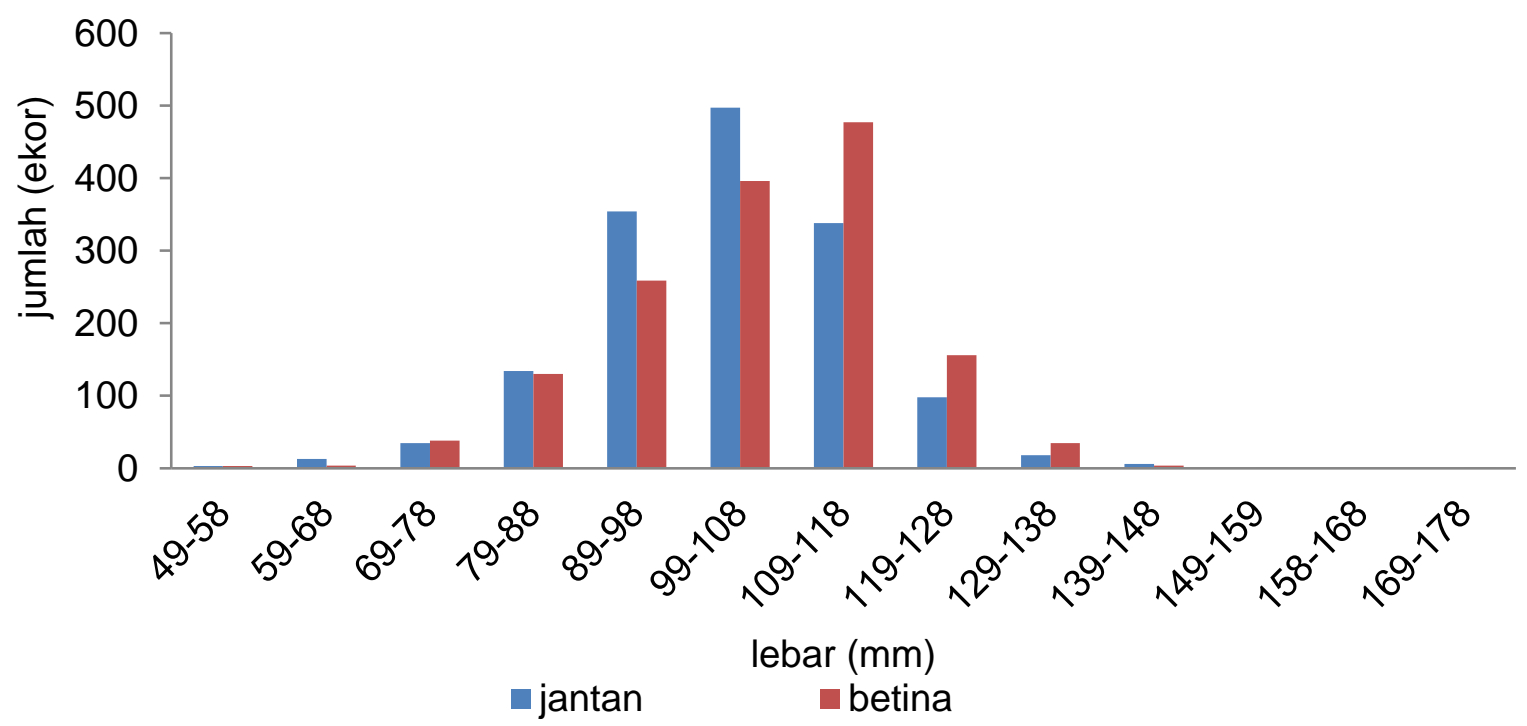

Gambar 1. Sebaran Lebar Karapas (mm) Rajungan (Portunus pelagicus)di Perairan Tunggulsari 
Tabel 1. Pola pertumbuhan Rajungan (Portunus pelagicus) di Perairan Tunggulsari

\begin{tabular}{lccccccl}
\hline $\begin{array}{c}\text { Rasio } \\
\text { Kelamin }\end{array}$ & $\mathrm{n}$ & $\mathrm{A}$ & $\mathrm{B}$ & $\mathrm{R}^{2}$ & $\mathrm{~W}=\mathrm{aL}^{\mathrm{b}}$ & $\begin{array}{c}\text { Faktor } \\
\text { Kondisi }\end{array}$ & $\begin{array}{l}\text { Pola } \\
\text { Petumbuhan }\end{array}$ \\
\hline Jantan & 1496 & 0,000778 & 2,4486 & 0,67 & $0,000778 \mathrm{~L}^{2,4486}$ & 102,0805 & $\begin{array}{l}\text { Allometrik } \\
\text { Negatif }\end{array}$ \\
Betina & 1504 & 0,000151989 & 2,7873 & 0,8063 & $\begin{array}{l}0,000151989 \\
\mathrm{~L}^{2,7873}\end{array}$ & 101,5223 & $\begin{array}{l}\text { Allometrik } \\
\text { Negatif }\end{array}$ \\
\hline Total & 3000 & 0,000113 & 2,8575 & 0,8092 & $0,000113 \mathrm{~L}^{2,8575}$ & 101,5428 & $\begin{array}{l}\text { Allometrik } \\
\text { Negatif }\end{array}$ \\
\hline
\end{tabular}

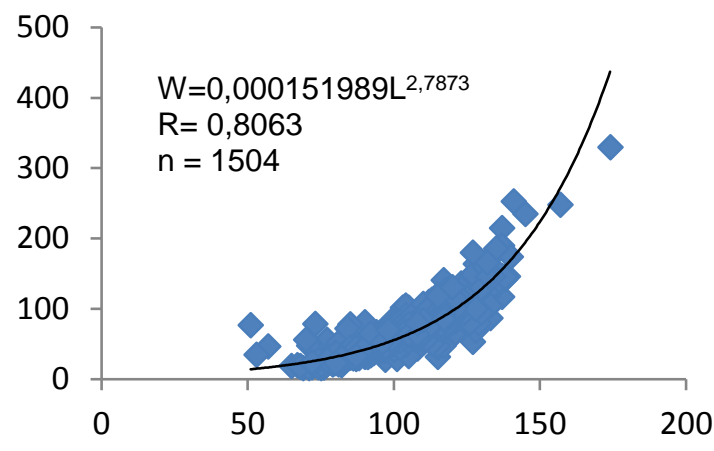

(a)

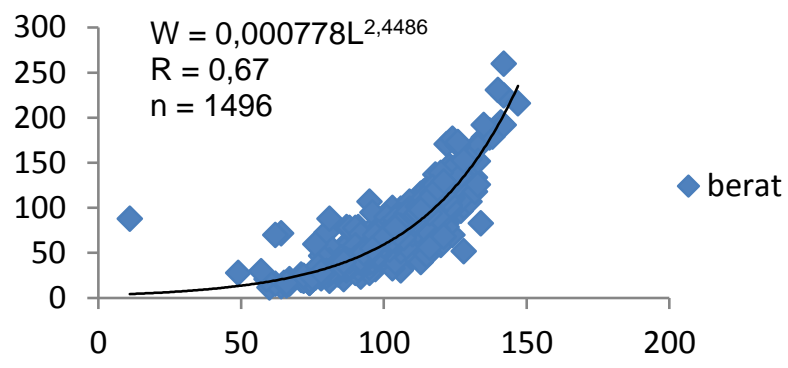

(b)

Gambar 2. Pola Pertumbuhan Rajungan (a) betina (b) jantan di Perairan Tunggulsari

rajungan yaitu jumlah dan ukuran makanan yang tersedia, oksigen terlarut, suhu, kualitas air, umur, dan ukuran organisme. Menurut Sara et al., (2016), suhu dan salinitas memegang peran penting dalam pertumbuhan rajungan. Rajungan pada kondisi bertelur banyak ditemukan pada suhu $15-25^{\circ} \mathrm{C}$ dan salinitas $30-40$ ppt. saat musim dingin (suhu rendah) rajungan cenderung tidak moulting. Pada suhu $24^{\circ} \mathrm{C}$ rajungan muda moulting setiap tiga minggu dan tumbuh hingga 7$10 \mathrm{~mm}$. Sedangkan pada suhu $20^{\circ} \mathrm{C}$ rajungan moulting dalam waktu 4 minggu. Tingkah laku biota dalam melakukan pergerakan aktif dan ruaya dapat mempengaruhi nilai b (Ibrahim et al.,2017 ). Ketika memasuki masa reproduksi, pertumbuhan akan relatif lebih lambat. Hal ini disebabkan karena sebagian energi yang didapat di alokasikan untuk perkembangan gonad (Lavina dan Buling, 2007).

Faktor kondisi dapat menggambarkan keadaan biota disuatu perairan. Rajungan jantan memiliki faktor kondisi sebesar 102,0805 sedangkan rajungan betina sebesar 101,5223 (Tabel 1). Nilai faktor kondisi $>100$, hal ini dapat disimpulkan bahwa kondisi rajungan jantan maupun betina di Perairan Tunggulsari baik. Hal ini sejalan dengan Muttaqin dan Dewiyanti (2016), suatu organisme dapat dikatakan baik bila memiliki faktor kondisi > 100 dan dapat dikatakan seimbang bila memiliki faktor kondisi 100. Perairan Tunggulsari menyediakan stok makanan yang cukup dan kepadatan predator yang seimbang. Hal ini sesuai dengan pernyataan Nasir et al., (2016), jika nilai berat relatif kurang dari 100 menandakan bahwa suatu perairan memilki stok makanan yang kurang dan predator yang tinggi, jika nilai berat relatif lebih dari 100 menandakan suatu perairan memiliki stok makanan berlimpah dengan tingkat predasi yang rendah.

Menurut Mainassy (2017), suhu sangat berpengaruh pada keberadaan biota air, peningkatan suhu dapat berdampak pada meningkatnya laju metabolisme biota air. Pada penelitian ini didapatkan suhu air dengan kisaran $27-30^{\circ} \mathrm{C}$. Suhu Perairan Tunggulsari sesuai dengan kriteria hidup rajungan. Menurut Juwana (1997), rajungan dapat tumbuh dengan baik pada suhu $27{ }^{\circ} \mathrm{C}$ $32^{\circ} \mathrm{C}$. Suhu perairan dapat berpengaruh pada reproduksi rajungan, tingkat reproduksi rajungan saat musim barat cenderung lebih tinggi dibanding dengan musim timur. Musim barat memiliki rentang suhu 30-+ 0,39 dan musim timur 28,2 -+ 0,39 (Ernawati et al., 2015). Salinitas pada lokasi penelitian berkisar antara 22 - 30 ppt. Rentang tersebut sangat baik untuk tumbuh kembang rajungan. Hasil ini lebih rendah jika dibanding dengan salinitas perairan pulau lancang kepulauan 
seribu dimana salinitasnya berkisar 29-31 ppt (Agus et al., 2016). Hal ini berkaitan dengan kemampuan rajungan dalam mengatur kondisi osmotik dalam tubuhnya yang hiposalin terhadap kondisi air laut yang hipersalin. Kemampuan ini membuat rajungan dapat hidup dengan rentang salinitas yang luas yaitu 11-53 ppt (Kurnia et al., 2014). pH perairan Tunggulsari yaitu berkisar antara 7,5-8,5. pH perairan cenderung basa hal ini sejalan dengan Putra et al., (2020), rajungan dapat tumbuh dan berkembang baik pada derajat keasaman yang relatif basa. Menurut KEPMENLH (2004), pH perairan yang baik untuk biota laut yaitu 7-8,5. Nilai pH berkaitan dengan kadar oksigen, bila $\mathrm{pH}$ rendah maka nilai oksigen dan alkalinitas tinggi dan nilai karbondioksida rendah. Pada Perairan Tunggulsari, rajungan ditemukan pada kadar kadar oksigen terlarut berkisar antara 8,3-8,8 mg/l. DO Perairan Tunggulsari tergolong baik. Kandungan oksigen terlarut merupakan faktor pembatas yang penting dalam kehidupan biota laut. Rajungan dapat hidup pada perairan dengan kisaran DO 5,1-9,2 mg/l (Agus et al., 2016). Pada Perairan Batu Licin, Bintan rajungan ditemukan pada kisaran DO 7,08-7,5. Nilai ini lebih kecil jika dibandingkan dengan kadar oksigen di Perairan Tunggulsari.

Pengelolaan sumberdaya rajungan mengacu pada Peraturan Pemerintah No 12 Tahun 2020 tentang Pengelolaan Lobster (Panulirus spp), Kepiting (Scylla spp), dan Rajungan ( Portunus pelagicus). PERMEN KP No. 12 Tahun 2020 Pasal 8 menyebutkan bahwa rajungan yang ditangkap tidak boleh kurang dari $10 \mathrm{~cm}$. Hasil penelitian menunjukkan bahwa masih terdapat rajungan yang berukuran kurang dari $10 \mathrm{~cm}$. Rajungan layak tangkap yaitu 1920 (64 \%) dan rajungan yang tidak layak tangkap sebesar 1080 (36 \%) (Gambar 3). Tertangkapnya rajungan yang tak layak tangkap berkaitan dengan kesadaran nelayan dan bakul dan kurangnya pengawasan terhadap pelaksanaan undang-undang. Nelayan di Perairan Tunggulsari telah mengetahui adanya peraturan tentang penangkapan rajungan, namun merasa sulit untuk dilakukan. Hal ini dikarenakan bakul masih menerima rajungan dengan segala kondisi dan ukuran (Komunikasi Pribadi).

Kondisi ini dapat diperbaiki dengan adanya pengelolaan sumberdaya rajungan secara bertahap. Menurut Budiarto et al. (2015), ada 5 tahap pengelolaan yaitu pengaturan ukuran dan kondisi rajungan yang boleh ditangkap, pengaturan musim penangkapan, pengendalian alat tangkap, pelaksanaan program restocking, dan peningkatan pengawasan terhadap peraturan yang berlaku. Selain itu perlu adanya perlindungan dan rehabilitasi habitat rajungan untuk mendukung pemijahan rajungan. Pembentukan suaka rajungan merupakan stategi pengelolaan rajungan berbasis konservasi yang bertujuan melindungi rajungan dan habitatnya (Hamid et al., 2017 ). Edukasi terhadap nelayan dan pengepul perlu dilakukan secara berkala untuk meningkatkan kesadaran nelayan tentang sumberdaya rajungan.

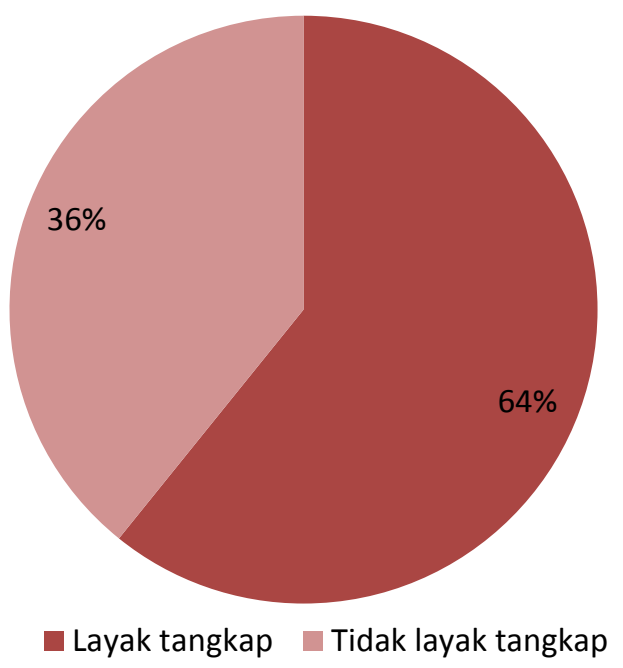

Gambar 3. Presentase Rajungan Layak Tangkap berdasarkan PERMEN KP No. 12 Tahun 2020 di Perairan Tunggulsari 


\section{KESIMPULAN}

Berdasarkan hasil penelitian dapat disimpulkan bahwa sumberdaya rajungan di Perairan Tunggulsari, Rembang memiliki distribusi kuran rajungan antara 49-178 mm dengan nilai modus pada ukuran 99-108 pada rajungan jantan dan 109 - 118 pada rajungan betina. Pola pertumbuhan rajungan yaitu allometrik negatif dengan nilai $b=2,8575$ dimana pertumbuhan lebar lebih cepat jika dibanding dengan pertumbuhan bobot. Berdasarkan penelitian terdapat $64 \%$ rajungan yang layak tangkap dan $36 \%$ rajungan yang tak layak tangkap meliputi rajungan muda berukuran $<10 \mathrm{~cm}$.

\section{DAFTAR PUSTAKA}

Afifah, N., Bengen, D.G., Sunuddin, A. \& Agus, S.B. 2017. Morfometri dan Sebaran Ukuran Rajungan (Portunus pelagicus, Linnaeus 1758) di Perairan Pulau Lancang, Kepulauan Seribu. Prosiding Pusat Riset Perikanan, pp.31-44.

Agus, S.B., Zulbainarni, N., Sunuddin, A., Subarno, T., Nugraha, A.H., Rahimah, I., Alamsyah, A. \& Rachmi, R., 2016. Distribusi Spasial Rajungan (Portunus pelagicus) pada Musim Timur di Perairan Pulau Lancang, Kepulauan Seribu. Jurnal IImu Pertanian Indonesia, 21(3): 209-218. DOI : 10.18343/jipi.21.3.209

Budiarto, A., Adrianto, L., \& Kamal, M. 2015. Status Pengelolaan Perikanan Rajungan (Portunus pelagicus) dengan Pendekatan Ekosistem di Laut Jawa (WPPNRI 712). Jurnal Kebijakan Perikanan Indonesia, 7(1):9-24. DOI : 10.15578/jkpi.7.1.2015.9-24

Ernawati, T. Boer, M. \& Yonvitner, Y. 2015. Biologi Populasi Rajungan (Portunus pelagicus) di Perairan Sekitar Wilayah Pati, Jawa Tengah. Bawal, 6(1):31-40. DOI: 10.15578/bawal.6.1. 2014.

Hamid, A. 2019. Habitat and Biological Aspects of Sentinel Crab, Podophthalmus vigil (Fabricus 1798) in Lasongko Bay, Southeast Sulawesi. Jurnal IImu Pertanian Indonesia, 24(1): 1-11. DOI: 10.18343/jipi.24.1.1

Hamid, A., Wardiatno, Y., Lumban, D.T.F. \& Riani, E. 2017. Pengelolaan Rajungan (Portunus pelagicus) yang Berkelanjutan berdasarkan Aspek Biologi di Teluk Lasongko, Sulawesi Tenggara. Kebijakan Perikanan Indonesia, 9(1):41-50. DOI: 10.15578/jkpi.9.1.2017.41-50

Hartnoll, R.G. 1982. Mating in the brachyura. Crustaceana. 16(2): 161-181

Ibrahim., P.S., Setyobudiandi, I. \& Sulistiono. 2017. Hubungan Panjang Bobot dan Faktor Kondisi Ikan Selar Kuning (Selaroides leptolepis) di Perairan Selat Sunda. Jurnal IImu dan Teknologi Kelautan Tropis, 9(2):577-584. DOI: 10.29244/jitkt.v9i2.19292

Kordi, M.G.H. 1997. Budidaya Air Payau. Dahara Prize. Semarang. 110-114.

Kurnia, R., Boer, M. \& Zairion 2014. Biologi Populasi Rajungan (Portunus pelagicus) dan Karakteristik Lingkungan Habitat Esensialnya sebagai Upaya Awal Perlindungan di Lampung Timur. Jurnal Ilmu Pertanian Indonesia. 19(1):22-28.

Lavina, A.F. \& Buling, A.S. 2007. The Propagation of the Mud Crab, Scylla serrate (Forskal) de Haan. Q. Res. Rep., Aquacul. Depart. SEAFDEC, (2):9-11.

Mainassy, M.C. 2017. The Effect of Physical and Chemical Parameters on the Presence of Lompa Fish (Thryssa baelama Forsskål) in the Apui Coastal Waters of Central Maluku District. Jurnal Perikanan Universitas Gadjah Mada, 19(2):61-66

Makahinda, F.R., Mantiri, R.O. \& Tolol, I.B.H., 2018. Pola Pertumbuhan Rajungan Portunus pelagicus pada Dua Lokasi yang Berbeda di Teluk Manado, Jurnal IImiah Platax, 6(1):149_ 159.

Muttaqin, Z. \& Dewiyanti, I. 2016. Kajian Hubungan Panjang Berat dan Faktor Kondisi Ikan Nila (Oreochromis niloticus) dan Ikan Belanak (Mugil chepalus) yang Tertangkap di Sungai Matang Guru, Kecamatan Madat, Kabupaten Aceh Timur. Jurnal IImiah Mahasiwa Kelautan Dan Perikanan Unsyiah, 1:397-403.

Nasir, M., Muchlisin, Z.A, \& Muhammadar, A.A. 2016. Hubungan Panjang Berat dan Faktor Kondisi Ikan Betutu (Oxyeleotris marmorata) di Sungai Ulim Kabupaten Pidie Jaya, Provinsi Aceh , Indonesia. Jurnal IImiah Mahasiswa Kelautan Dan Perikanan Unsyiah, 1(3):262-267. 
Nugraheni, D.I., Fahrudin, A. \& Yonvitner. 2015. Variasi Ukuran Lebar Karapas dan Kelimpahan Rajungan (Portunus pelagicus Linnaeus) di Perairan Kabupaten Pati. Jurnal IImu dan Teknologi Kelautan Tropis, 7(2):493-510.

Putra, M.J.H., Subagyo \& Nuraini, R.A.T. 2020. Biologi Rajungan Ditinjau dari Aspek Morfometrik dan Sex Ratio yang Didaratkan di Perairan Rembang. Journal of Marine Research. 9(1):6574. DOI :10.14710/jmr.v9i1.24729

Republik Indonesia, Peraturan Menteri Perikanan dan Kelautan Nomor 12/ PERMEN-KP /2020 tentang Pengelolaan Lobster (Panulirus spp), Kepiting (Scylla Spp.), Rajungan (Portunus pelagicus spp),

Republik Indonesia, Peraturan Menteri Perikanan dan Kelautan Nomor 70/ KEPMEN-KP 2015 tentang Rencana Pengelolaan Perikanan Rajungan di Wilayah Pengelolaan Perikanan Negara Republik Indonesia.

Sara, L., Muskita, W.H. \& Astuti, O. 2016. The Reproductive Biology of Blue Swimming Crab Portunus pelagicus in Southeast Sulawesi waters, Indonesia. Bioflux, 9(5):1102- 1112.

Walpole, R.E. 1992. Pengantar Statistika Edisi Ke- 3. Gramedia Pustaka Utama. Jakarta.

Wibowo, N.G.A., Suryono, C.A., \& Pratikto, I. 2019. Biologi Rajungan Portunus pelagicus Linnaeus, 1758 (Crustacea: Portunidae) Ditinjau dari Aspek Distribusi Ukuran dan Parameter Pertumbuhan di Perairan Rembang, Jawa Tengah. Journal of Marine Research, 8(4):402408. DOI : 10.14710/jmr.v8i4.24539 